\title{
Successful Workplace Learning: Moderating Effect of Organizational Culture
}

\author{
Younes Daryoush (corresponding author) \\ PhD student in Human Resource Development, Department of Professional \\ Development and Continuing Education Faculty of Educational Studies, Universiti Putra \\ Malaysia \\ Tel: 60-17-8881068Ｅ-mail: younes.daryoush91@ gmail.com
}

\author{
Abu Daud Silong \\ Professor PhD in Human Resource Development, Department of Professional \\ Development and Continuing Education Faculty of Educational Studies, Universiti Putra \\ Malaysia
}

Tel: 60-3-89468250 E-mail: adsz@ace.upm.edu.my

\section{Zohara Omar}

PhD in Human Resource Development, Department of Professional Development and Continuing Education Faculty of Educational Studies, Universiti Putra Malaysia

Tel: 60-3-89467911 E-mail: zoharah@educ.upm.edu.my

Jamilah Othman

Dept of Professional Development and Continuing Education, Universiti Putra Malaysia

Tel: 60-3-8946-6000 E-mail: jamilah@educ.upm.edu.my

Accepted: Sep 08, 2013 Published: October 01, 2013

Doi:10.5296/ijhrs.v3i4.4180

URL: http://dx.doi.org/10.5296/ijhrs.v3i4.4180

\begin{abstract}
A main point of this study was that successful workplace learning is depended on workplace environment and its relationship with job performance will be improved in certain organizational culture values and practices. We hypothesized that the relationship between formal, informal and incidental workplace learning with task and contextual performance would be higher in result-oriented cultures. These five hypotheses were supported. We used interaction effect software by examining the strength of relationship in five level of result oriented culture. Our results indicate that these result culture value complement relationship between workplace learning and job performance.
\end{abstract}

Keywords: workplace learning; task performance; contextual performance; organizational culture 


\section{Introduction}

Increasing intensity of competition among organizations in the current century, it is always followed Ways to gain competitive advantage and resultant success in the field of competition. Workplace learning is one of the tools Managers gain a competitive advantage for organizations are now considered (Rothwell, 2002; Cromwell and Kolb, 2004; Heilmann, 2007). Nowadays, organizations have changed based on new knowledge and technology. Employees have to constantly update their skills, and knowledge (Lin, 2008), and organizations have accepted heir human resources as essential source of sustainable development (Aragon-Sanchez et al., 2003; Park, 2009).

The theoretical argument linking workplace learning to job performance is a well-known theory. "On-the-Job Training" gives organizations an efficient and effective way to meet the demand for skill by the continuous changes in environment and technology (Tracey et al., 1995; Barron et al., 2002; Park, 2009). Workplace learning includes training as formal learning, informal and incidental learning can achieve both individual and organizational performance by individual learning. It would be more logical o employ the term 'workplace learning' more than 'training,' as it would demonstrate the various learning activities (Park, 2009).

Workplace learning literature that studied learning outcomes as result of workplace learning, they reported various outcomes such as skills and abilities, employees' work performance, motivation to transfer learning, knowledge, organizational performance, and organizational commitment (Lankau and Scandura, 2002; Enos et al., 2003; Tsai and Tai, 2003; Velada et al., 2007; Dysvik and Kuvaas, 2008; Maurer et al., 2008; Park, 2009). Many researchers argue about importance of learning for improving job performance but they mentioned that is not sufficient(Bates et al., 2000; Velada et al., 2007). The performance elements of HRD with learning build the expertise construct(Swanson and Holton, 1999). They explained the expertise as "human behaviours, having effective results and optimal efficiency, acquired through study and experience within a specialized domain" (p. 26). It shows that we need to study moderating effect of context variable.

The research conducted by Aragon-Sanchez et al.(2003) examines the effects of training program on performance. They claimed that training has positive relationship with performance. They conclude that organizations ignore the contribution of training to goal achievement and the effect of training on effectiveness and profitability. In addition, the different types of training activity have different effect on effectiveness and the results of training depend on many factors(Aragon-Sanchez et al., 2003). However, they did not mention about these factors. One question needs to be asked, do organizational factors affect on results of training? Which conditions cause the positive relationship between training and job performance?

In the human resource development, this divide has been characterized as the "micro" domain where the focus is on the individual and the "macro" domain where the focus is on the organization(Klein et al., 1999). Multilevel theory integrates the two by acknowledging the influence of the organization on the individual, and vice versa. From the multilevel perspective, then, neither level is more or less important. In addition, individual learning would 
be seen as an essential of achieving individual and organizational goals. Thus, multilevel theories may illuminate the steps organizational actors may take, individually and collectively, to yield organizational benefits(Klein et al., 1999).

Consistent with the line of research on moderators of the workplace learning -performance relationship, we suggest that the variability in the predictive power of workplace learning across studies may be accounted for by how contextual factors moderate the effects of dispositional factors on employee behaviors. The person-workplace interaction framework has suggested the importance of considering the interactive effects of person and organization variables in shaping human behaviors (cf. Eraut, 2002; Clarke, 2005; Elfenbein and O'Reilly, 2007). Magee (2002)suggests that organizational culture is an important contextual variable and recommends that individuals actualize their potential when organization culture is compatible with their own capabilities, workplace values, and interests.

In workplace learning research ,there is suggestive evidence that organizational contextual variables would moderate the workplace learning-performance relationship. For example, time pressure, learning contexts, and situational variables point to the importance of different contexts in shaping the workplace learning-performance relationship(Yiing and Ahmad, 2009; Joo, 2012).

Adopting the person-culture interactive framework, we theorize how a contextual factororganizational culture - would moderate the relationship between workplace learning and two types of job performance - contextual performance (Borman and Motowidlo, 1997) and task performance (Scott and Bruce, 1994).

We discuss why employees learning are more likely to attend to contextual variables. We operationalized contextual cues as result orientation culture (Beugelsdijk et al., 2006). We argue that the existence of strong result-oriented culture in organizations will activate workplace learning and focus it more on high task and contextual performance, an effect that will be weak in cultures with low levels of this orientation. In the following sections, we first examine the workplace learning- job performance relationship and then result orientation as cultural characteristic. Finally, we consider the workplace learning-job performance relationship within cultures characterized by different levels of result orientation.

\section{Theoretical background and hypotheses}

A considerable amount of literature has been published on training as formal workplace learning, but few studies are in other types of workplace learning such as informal workplace learning and incidental workplace learning. The variety of workplace learning definitions shows that the nature of workplace learning is contextual and collaborative (Brown and Duguid, 1991); the key concept is learning, and the importance of informal is more than formal training(Moon and $\mathrm{Na}, 2009 \mathrm{~b}$ ).

The theory of "work adjustment" claims that individuals and environments impose requirements on one another and that "successful" work relations are the result of adjustments intended to create a state of correspondence between individual and environmental characteristics (Dawis and Lofquist, 1984; O'Reilly III et al., 1991). Although the theory has primarily been used to study person-culture fit, it was clearly intended to apply 
to specific organizational settings as well. The existing body of support generated for theory of work adjustment seems directly applicable to the developing body of research on personorganization fit(Elfenbein and O'Reilly, 2007).

Fit with an organization's culture typically focuses on similarity in values and practices. Although streams emphasize fit and draw on similar underlying theories, little research investigates both simultaneously. In a field study with intact teams, cultural fit had independent effects on subsequent performance; however, "deeper" value fit effects were stronger than "surface" demographic fit(Sarris and Kirby, 2005; Elfenbein and O'Reilly, 2007).

There is evidence that person-culture fit, examine as either person-organization or person-group fit is linked with positive work performance and attitudes (O'Reilly III et al., 1991; Cable and Judge, 1997; Kristof-Brown and Stevens, 2001). The benefit of understanding fit for both the organization and employee to select people based on the values that define the organization's culture (Elfenbein and O'Reilly, 2007).

A useful way to conceptualize how culture influences the behavior of employees can be found in the congruence perspective. This point of view is based on the idea that employees adjust and adapt better to their work environment when the organization's characteristics fit their employee orientations (O'Reilly III et al., 1991; Bretz Jr and Judge, 1994).

Elfenbein and O'Reilly (2007), increased fit in terms of person-culture can lead to higher levels of acceptance and social integration(e.g, O'Reilly III et al., 1989), individual performance (e.g., Kristof-Brown \& Stevens, 2001). One research discussed with managers and engineers about learning at work with new comers and effect of learning on job performance, retention, and satisfaction. The result showed that how the social norms and organizational culture values affect on new employees (Poell and Woerkom, 2011).

Some organizations emphasize process and/or quality, and innovation, but others emphasize outcomes and efficiency. In this case, what is emphasized in a specific context, for example, in terms of organizational culture, may shape the relationship between workplace learning and task performance?

\section{Result-oriented culture}

Organizational culture is a set of beliefs and values shared by members of the same organization that influences their behaviors (Schein, 1990; O'Reilly III et al., 1991; Schein, 1996). Culture reflects common ways of thinking and behaving. According to O'Reilly III et al. (1991), result-oriented culture is demanding and bent on achieving results. A result-oriented culture emphasizes efficiency and productivity, stresses the importance of getting things done, presses for on-time delivery of products and services, and maintains a faster pace than that of competitors while simultaneously controlling operational costs (Miron et al., 2004). Hofstede (1993) noted that individual cultural orientation affects learning outcomes through learning interactions.

This approach suggests that the result orientation competes with efficiency. The moderating effect of result oriented culture presents a synergistic system whereby cultural orientation can be mutually reinforcing. It may be necessary for organizations to provide rules, routines, and standards, and at the same time emphasize the creation of knowledge. Our intention is to 
compare the competing, independent, and balanced approaches in affecting task and contextual performance. The first three hypotheses reflect our prediction regarding the moderating effect of result orientation on relationship between workplace learning and task performance and the second three hypotheses reflects our prediction regarding the moderating effect result oriented on workplace learning-contextual performance.

\section{Culture as a moderator of the workplace learning-job performance relationship}

Considering the main characteristics of workplace learning, it provides knowledge and expertise despite the consistent positive effects of workplace learning on performance, the workplace learning-performance relationship has variability. We suggest that this variability can be examined in terms of a contextual variable such as organizational culture values.

As discussed above, workplace learning includes formal, informal, and incidental. These characteristics suggest that employees' learning is more likely to sustain consistent and inordinate effort in completing their work. With knowledge and expertise, it is more likely that employees perform well in their jobs.

Klein et al.(1999) argued organizations are multilevel in nature since employees work in groups and teams within organizations. Thus, it is inevitable to have level issues in organizational studies. Garavan et al.(2004) also claimed that HRD researchers must consider to the difference between the level of theory and the level of measurement; while the level of theory is associated with the targets, the level of measurement emphasizes on the sources of data.

For example, where data is gathered from individuals to study organizational constructs (such as organizational culture to examine how organizational culture influences the relationship between workplace learning and job performance). Level issues must be recognized (Park, 2009).

The foundational context to transfer learning to performance is organization culture (Watkins and Marsick, 1997) because a desirable learning culture may affect diverse organizational issues, such as leaders' behaviors as well as job characteristics to produce positive organizational outcomes. All these factors are critical for improving employees' job performance, so there is a need for greater focus on understanding the mechanisms through which social and organizational contexts influence employees' job performance (Joo, 2012).

According to Holton et al. (2007), learning can improve job performance but transfer of learning to behavioural change is depending on many factors. One of the most significant factors that influence on the relationship between learning and job performance is organizational culture that we can see in Holton model as environmental factor. (Elfenbein and O'Reilly(2007) argued that employee-culture fit can explain by adjustment theory in organization context which seems control the employee behaviour. Therefore after learning we can assume that whether organization gives them the opportunity for applying learning to job or not. It is time to come this idea that what is the effect of organizational culture values, for instance, organization buys new equipments and provide relayed training program as formal learning for using those equipments. What will it happen if organization has powerful result-oriented value? 
However, the relationship between workplace learning and job performance is commonly accepted in organizations, but few studies have investigated how specific variable can affect on relationship between workplace learning and job performance (Reio and Callahan, 2004; Kramer, 2007; Moon and Na, 2009a; Chughtai and Buckley, 2011). Base on literature review, there is little understanding about how relationship between workplace learning and job performance is influenced by organizational culture. Several studies have recognized a positive relationship between training and organizational performance, such as organizational growth, productivity, quality, and employees' affective state, organizational commitment and job satisfaction (Rowden, 2002; Jacobs and Park, 2009; Arnolds et al., 2010; Cheung, 2011; Keith and Frese, 2011). However, most studies have argued on training and development as a formal type of workplace learning rather than comprehensively including informal, incidental and formal learning in the workplace. Hence, we propose the following hypotheses:

H1a: A result-oriented culture moderates the relationship between formal workplace learning and contextual performance.

H1b: A result-oriented culture moderates the relationship between informal workplace learning and contextual performance.

H1c: A result-oriented culture moderates the relationship between incidental workplace learning and contextual performance.

In addition to replicating the positive relationship between workplace learning and contextual performance, we also examine the less-studied relationship between workplace learning and task performance. Task performance can be defined as intentional idea generation, idea promotion, and idea realization within a work role, work group, or organization in order to improve individual, group, or organization performance (Scott and Bruce, 1994; Ali et al., 2002; Janssen and Van Yperen, 2004; Park, 2009).

Workplace learning includes activities that reflect being skillful and knowledgeable for performing task (Meador, 2008). As these activities reflect caring for the organization's success or goal accomplishment, experienced employees may also demonstrate task performance given the appropriate organizational context.

Similarly, an organizational context can serve as an important supporting function for employee learning(Lynch et al., 2006).

Task performance is more likely to occur when the culture supports results (Ang et al., 2007). Just as a result-oriented organizational culture can activate an employee's learning to perform on a higher level. This is because a culture tends to provide employees with more flexibility in determining the best way to accomplish tasks and gives them the discretion to take risks (Elfenbein and O'Reilly, 2007). Accordingly, we propose the following hypotheses:

$\mathrm{H} 2 \mathrm{a}$ : A result-oriented culture moderates the relationship between formal workplace learning and task performance.

$\mathrm{H} 2 \mathrm{~b}$ : A result-oriented culture moderates the relationship between informal workplace learning and task performance.

H2c: A result-oriented culture moderates the relationship between incidental workplace learning and task performance. 


\section{Methods}

This study was conducted from 13 subsidiaries of the public sector organization in the areas of complex C, Putra Jaya, in Malaysia. Two organizations selected randomly. The data were obtained from the Ministry of Science, Technology and Innovation (MOSTI) and Public Sector Department (JPA), Panel surveys, which were conducted in 2012 in Malaysia. All departments from two organizations in Putra Jaya participate in this study. The sample selected by random sampling from these two organizations. The population size is estimated 590 officers from JPA and 273 officers Subject of study from MOSTI. According to the proportion of male and female the sample with the Morgan table is counted which are 217 and 152 that was totally 369. The sample was selected by random sampling from these two organizations.

Respondents were assured that their responses would be kept confidential. A pre-addressed, postage paid envelope allowed participants to return their completed questionnaire directly to the researchers. By deleting the unmatched dyads, the final sample consisted of 322 employees. The response rate for the officers' sample was $87 \%$, respectively.

\subsection{Subjective measures}

To assure measure equivalence in the English versions of the questionnaire, researcher conducted interview by officers and employed pilot test. Expert judges in English also examined the questionnaire to ensure that the items were understandable in context.

Respondents were allowed to self-report their own attitude and perception of reality. Selfreporting surveys allow respondents to record their own perceptions of reality. The reason is that "behavior and attitudes are determined not by objective reality but by actors' perceptions of reality, it is appropriate to focus on the latter" (Ashkanasy et al., 2000, p.133).

Job performance is of two dimensions including: Task and contextual performance(Motowidlo and Van Scotter, 1994). To measure these concepts, two selfreported questionnaires consisting of 22 items $(a=0.90)$ were employed. Questionnaire of task performance included 13 items while there were 9 items to measure contextual performance. To identify respondents' perception of job performance, they were asked to indicate the degree of their agreement on a five-point Liker scale $(1=$ Not at all likely to $5=$ Extremely likely).

To measure the workplace learning variable, 17 items developed by Rowden (2002) were used. Participants were asked to indicate their agreement with statements on workplace learning on a five-point Liker scale ( $1=$ Strongly Disagree to $5=$ Strongly Agree). Workplace consists of three dimensions: 1) formal learning which was measured using 4 items to identify participants' perceptions of planned, organized training activities $(\mathrm{a}=.87), 2)$ informal learning which was measured with 8 items to identify participants' perception of disorganized and unplanned activities or spontaneous demonstrations leading to perception of job learning $(\mathrm{a}=.83)$, and $(3)$ incidental learning which was measured with 5 items $(\mathrm{a}=.85)$ to identify participants' perceptions of normal workplace activities.

Dimensions of organizational culture which have been derived from O'Reilly et al.'s study (1991) include innovation orientation, outcome or results orientation $(\mathrm{a}=0.79)$ (Hofstede $e t$ 
al., 1990; Verbeke, 2001), team orientation and stability orientation. For the present study, measurement employee or people orientation and communication orientation or open system developed by Hofstede et al. (1990) are adopted. These dimensions have been frequently used and supported in many studies (Denison, 1996; Christensen and Gordon, 1999; Detert et al., 2000).

\section{Results}

The individual measures used in the present study had sufficient internal consistency. Subordinates provided information on workplace learning only. To examine the psychometric properties of the variables from the same source (i.e. employees), we conducted a confirmatory factor analysis (CFA) on these variables using AMOS 18. As we had quite a few indicators in our model (44) relative to the sample size after deleting cases with missing data ( $\mathrm{N}=322$ ), we simplified the measurement model by reducing the number of indicators for some of the constructs. The number of items was reduced by averaging the items with the highest and lowest factor loadings from our confirmatory factor analyses. This procedure of reducing the number of indicators has been frequently used in the structural equation modeling literature for increasing statistical power (Mathieu and Farr, 1991; Mathieu et al., 1993). The fit indices yielded acceptable results $\left(X^{2}=1091.31, \mathrm{df}=449, \mathrm{p}<0.01 ; \mathrm{CFI}=0.90\right.$, IFI $=0.91 ;$ SRMR=0.056; RMSEA=0.07).

Table 1 presents the means, standard deviations, and coefficient alpha reliabilities for the variables used in this study. Table 2 presents the moderated regressions to test our hypotheses (Baron and Kenny, 1986) by conducted interaction effect software distributed by D. Sober, (2013) . We followed the same general procedure for each of the moderated multiple regressions. The first step consisted of entering result orientation culture as control variable as one block into the equation. In the second step, we entered the two independent variables of workplace learning and result-oriented. On the final step, we entered the cross-product term. Support for a moderating effect exists if the $\mathrm{R}^{2}$ for the interaction term is significant. To support the specific effect hypothesized, the slopes of the interaction terms must be in the predicted direction. 


\section{Macrothink}

International Journal of Human Resource Studies

ISSN 2162-3058

2013, Vol. 3, No. 4

Table 1. Means, standard deviations, reliabilities, ${ }^{\mathrm{a}}$ and correlations

\begin{tabular}{|l|c|c|c|c|c|c|c|c|}
\hline Variable & Mean & SD & $\mathbf{1}$ & $\mathbf{2}$ & $\mathbf{3}$ & $\mathbf{4}$ & $\mathbf{5}$ & $\mathbf{6}$ \\
\hline 1. Formal Learning & 3.36 & 0.66 & $(0.87)$ & & & & & \\
\hline $\begin{array}{l}\text { 2.Informal } \\
\text { Learning }\end{array}$ & 4.05 & 0.54 & $0.24^{*}$ & $(0.83)$ & & & & \\
\hline $\begin{array}{l}\text { 3.Incidental } \\
\text { Learning }\end{array}$ & 3.21 & 0.48 & $0.38^{* *}$ & $0.52^{* *}$ & $(0.85)$ & & & \\
\hline $\begin{array}{l}\text { 4.Result-oriented } \\
\text { culture }\end{array}$ & 3.01 & 0.39 & $0.34^{* *}$ & $0.57^{* *}$ & $0.40^{* *}$ & $(0.79)$ & & \\
\hline 5.Task performance & 3.10 & 0.35 & $0.25^{*}$ & $0.45^{* *}$ & $0.43^{* *}$ & $0.46^{* *}$ & $(0.88)$ & \\
\hline $\begin{array}{l}\text { 6.Contextual } \\
\text { performance }\end{array}$ & 3.83 & 0.46 & $0.25^{*}$ & $0.40^{* *}$ & $0.36^{* *}$ & $0.45^{* *}$ & $0.59^{* *}$ & $(0.92)$ \\
\hline
\end{tabular}

${ }^{a}$ Coefficient a reliabilities estimates are shown on the diagonal. ${ }^{*} \mathrm{p}<0.05 ; *{ }^{*} \mathrm{p}<0.01$

As shown in Table 2, five one-way interaction terms were significant. However, the one one-way interaction between incidental workplace learning, result-oriented, and task performance is not significant.

Table 2. One-way interaction effects

\begin{tabular}{|l|c|}
\hline \multicolumn{1}{|c|}{ Path } & $\begin{array}{c}\text { Main } \\
\text { Effect }\end{array}$ \\
\hline FWL $\times$ ROC $\rightarrow$ Task Performance & $.10^{*}$ \\
\hline INFWL $\times$ ROC $\rightarrow$ Task Performance & $.11^{* *}$ \\
\hline INCWL $\times$ ROC $\rightarrow$ Task Performance & $.12^{* *}$ \\
\hline FWL $\times$ ROC $\rightarrow$ Contextual Performance & $.15^{* *}$ \\
\hline INFWL $\times$ ROC $\rightarrow$ Contextual Performance & $.12^{* *}$ \\
\hline INCWL $\times$ ROC $\rightarrow$ Contextual Performance & .07 \\
\hline \multicolumn{2}{|c|}{$* *$ Correlation is significant at the 0.01 level } \\
$*$. Correlation is significant at the 0.05 level
\end{tabular}

Figure 1(a,b) shows the interactions of two types of workplace learning and result oriented culture with contextual performance. Figure 1(a) shows that when result-oriented culture is low, there is no relationship between formal workplace learning and contextual performance. However, with high levels of result-oriented culture, the formal workplace learning shows high level of contextual performance. Figure 1(b) shows that when the result-oriented culture is high, more employee informal learning shows high level of contextual performance. Moreover, there is no significant interaction effect between incidental workplace learning and result oriented culture with contextual performance. 
(a)

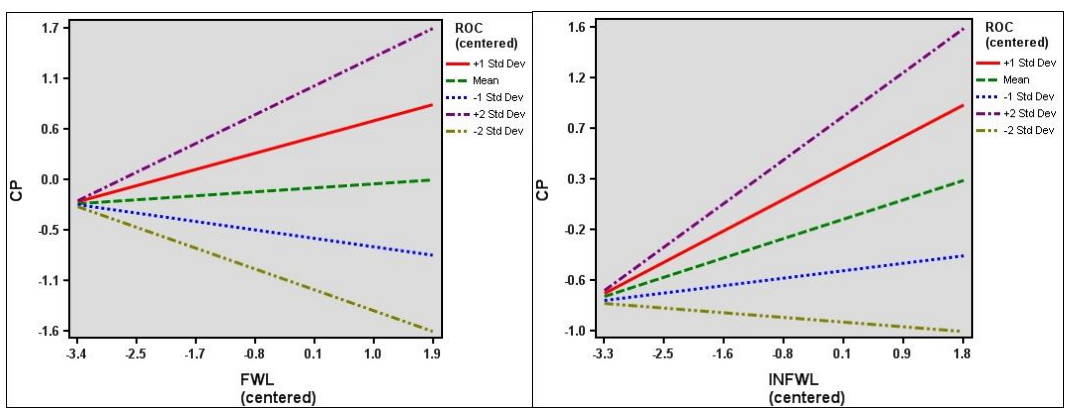

Figure 1. (a) CP: Contextual Performance, FWL: Formal Workplace Learning; ROC: Result-Oriented Culture. (b) CP: Contextual Performance, INFWL: Informal Workplace Learning; ROC: Result-Oriented Culture.

Figure 2(a,b,c) shows the interactive relationships on task performance.

Figure 2(a) shows that when result-oriented culture is low, the relationship between formal workplace learning and task performance is low. However, with high levels of result-oriented culture, the formal workplace learning shows high level of task performance. Figure 2(b) shows that when the result-oriented culture is high, more employee informal learning shows high level of task performance. Moreover, based on Figure 2(c) there is a significant interaction effect between incidental workplace learning and result oriented culture with task performance.

(a)

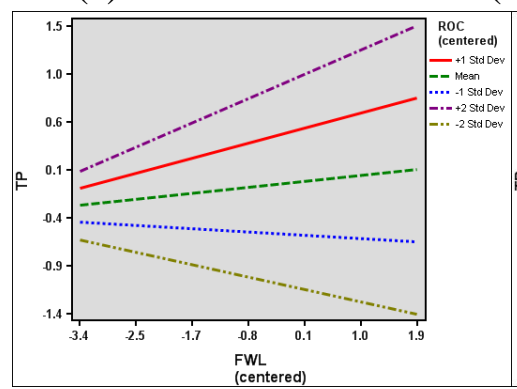

(b)

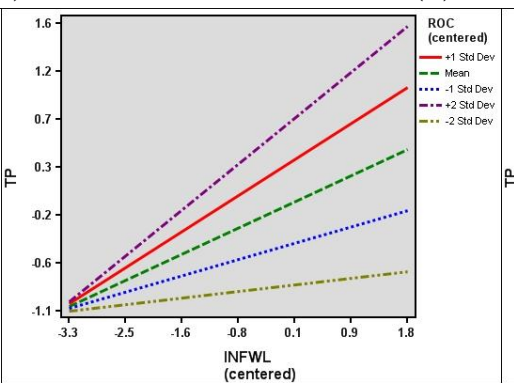

(c)

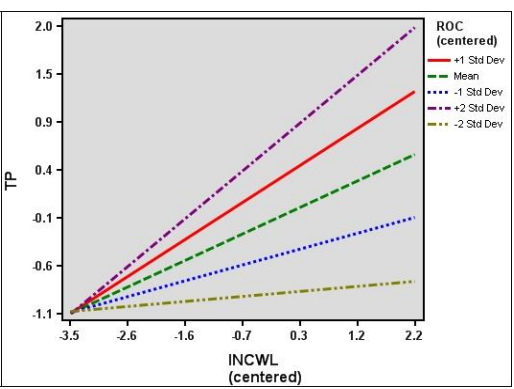

Figure 2. (a) TP: Task Performance, FWL: Formal Workplace Learning; ROC: Result-Oriented Culture. (b) TP: Task Performance, FWL: Formal Workplace Learning; ROC: Result-Oriented Culture. (c) TP: Task Performance, FWL: Formal Workplace Learning; ROC: Result-Oriented Culture.

In summary, the form of the relationship supports the five hypotheses as they reveal that workplace learning activities showed higher task and contextual performance when result-oriented culture is high result than when this culture orientation is low.

\section{Discussion and conclusions}

Using multilevel theory, we hypothesized that workplace learning and contextual performance would be positively related when accompanied by a result-oriented culture and 
that workplace learning and task performance would be strongly related when accompanied by a result-oriented organizational culture. The results of our study show that the two-way interactions were significant. However, workplace learning was positively related to contextual (interpersonal facilitation) and task performance when the unit's culture promotes results.

The results of our study suggest that emphasizing one only (result-oriented culture) for employee learning is not good enough for positive organizational results such as higher contextual or task performance. Rather, it is important for organizations to focus on three types of workplace learning such as informal, incidental and formal learning. In support of the interaction approach, our study suggests that the cultural values of result orientation can co-exist (Shader, 1990; Ali et al., 2002; Marsick and Watkins, 2003; Yiing and Ahmad, 2009; MacIntosh and Doherty, 2010; Joo, 2012; Wang et al., 2012). Thus, the norms for producing results on time with flexibility that ensures proper conditions to be best for employee learning in our context.

\section{Theoretical contributions}

Results of our study make potential contributions to the learning and performance literature. First, we have identified organizational culture, in addition to psychological context and work effort (Mintu-Wimsatt, 2002), social skill, and social skill awareness (Hochwarter et al., 2006) as moderators of the workplace learning and work outcome relationship. Second, as in Wang et al.(2012), we examine organizational culture as another theoretically relevant moderator via multilevel theory and extend the theoretical perspective to suggest that the relationships of workplace learning to outcomes depend on the specific organizational context. Variability in contexts can activate individual learning to act in ways that are consistent with the environment they are in. Third, as evidenced by the two-way interactions, our results suggest that a result-oriented culture has neither independent nor competing effects on employees learning for higher contextual or task performance. That is, when the result culture is strong the relationships between workplace learning with interpersonal facilitation and task performance are strong. It is when cultural norms are strong that the relationships between workplace learning and contextual performance and task performance are strong. These cultural norms do have complementary effects in activating workplace learning to make greater contributions to the organization. It is possible that when there is little or no result orientation, employees learning may try too hard and not be focused enough. With a result orientation, three types of workplace learning are much more focused and can direct their effort at task performance. Our results indicate that the cultural orientations have complementary effects rather than having competing or independent effects on workplace learning.

Consistent with previous meta-analytic studies, workplace learning was positively related to contextual performance across jobs and occupations (Reio and Wiswell, 2000; Somech and Drachâ€• Zahavy, 2004; Jo and Joo, 2011). Thus, people who see themselves as hardworking, reliable, and organized appear to perform better than those who believe they do not possess these characteristics. These employees learning also showed higher levels of performance in our sample. Future studies may go beyond studying the associations between workplace 
learning with task and contextual performance to include organizational performance. This is because, in order to be competitive, organizations need to find the right balance between focusing on efficiency and productivity versus giving employees the freedom to adapt to problems and opportunities.

\section{Limitations and future research}

This study has several limitations. The first is that common method bias may be a concern. With the exception of workplace learning, information on most variables in this study was provided by the employees. We also followed the recommendations from Podsakoff et al.(2003) for conducting the Harman one-factor test. Results of this test indicated a bad fit and, therefore, we do not believe that common method variance affected our results. Furthermore, common method variance should not be a significant threat in a study that tests moderating effects (i.e. different relationships at different levels of a specified variable). Brockner et al.(1997) note that if common method variance explains significant relationships, there is no reason why there should be a significant relationship at one level of a variable but not at another.

Second, our study was conducted in two organizations. Although this may reduce the generalizability of our findings, testing our hypothesized model in two organizations reduces the likelihood that contextual factors such as ministry type might affect our results. However, our findings are consistent with other studies because workplace learning was also positively related to in-role performance and contextual performance. Future studies should examine other contextual situations that may also activate higher levels of contribution in conscientious individuals.

Practical implications and conclusion our findings, together with recent research, suggest the utility of examining the role of theoretically relevant contextual effects in moderating the relationship between workplace learning and job performance. Our results indicated that strong learner can have strong task performance provided that they work in the appropriate work context. It is not enough simply to select the right people and place them in the appropriate jobs. It is also important to provide the appropriate norms or cultural values that can cultivate people's performance.

\section{References}

Ali, I. M., Pascoe, C. and Warne, L. (2002). Interactions of Organizational Culture and Collaboration in Working and Learning. Educational Technology \& Society 5(2): 2002.

Ang, S., Van Dyne, L., Koh, C., Ng, K. Y., Templer, K. J., Tay, C. and Chandrasekar, N. A. (2007). Cultural Intelligence: Its Measurement and Effects on Cultural Judgment and Decision Making, Cultural Adaptation and Task Performance. Management and Organization Review 3(3): 335-371.

Aragon-Sanchez, A., Barba-Aragon, I. and Sanz-Valle, R. (2003). Effects of Training on Business Results. International Journal of Human Resource Management 14(6): 956-980. 
Arnolds, C., Boshoff, C., Mazibuko, N. and Klemz, B. (2010). The Motivational Impact of Job Security, Recognition, Monetary Incentives and Training on the Job Performance of Blue-Collar Employees. South African Journal of Labour Relations 34(1): 86-102.

Ashkanasy, N. M., Broadfood, L. and Falkus, S. (2000). Questionnaire Measures or Organizational Culture.

Baron, R. M. and Kenny, D. A. (1986). The Moderator and Mediator Variable Distinction in Social Psychological Research: Conceptual, Strategic, and Statistical Considerations. Journal of personality and social psychology 51(6): 1173.

Barron, J. M., Berger, M. C. and Black, D. A. (2002). On-the-Job Training. Books from Upjohn Press.

Bates, R. A., Holton III, E. F., Seyler, D. L. and Carvalho, M. A. (2000). The Role of Interpersonal Factors in the Application of Computer-Based Training in an Industrial Setting. Human Resource Development International 3(1): 19-42.

Beugelsdijk, S., Koen, C. I. and Noorderhaven, N. G. (2006). Organizational Culture and Relationship Skills. Organization studies 27(6): 833-854.

Borman, W. C. and Motowidlo, S. J. (1997). Task Performance and Contextual Performance: The Meaning for Personnel Selection Research. Human Performance 10(2): 99-109.

Bretz Jr, R. D. and Judge, T. A. (1994). Personâ€“Organization Fit and the Theory of Work Adjustment: Implications for Satisfaction, Tenure, and Career Success. Journal of Vocational behavior 44(1): 32-54.

Brockner, J., Siegel, P. A., Daly, J. P., Tyler, T. and Martin, C. (1997). When Trust Matters: The Moderating Effect of Outcome Favorability. Administrative science quarterly: 558-583.

Brown, J. S. and Duguid, P. (1991). Organizational Learning and Communities-of-Practice: Toward a Unified View of Working, Learning, and Innovation. Organization science: 40-57.

Cable, D. M. and Judge, T. A. (1997). Interviewers' Perceptions of Person-Organization Fit and Organizational Selection Decisions. Journal of Applied Psychology 82(4): 546.

Cheung, S. Y. (2011). Refinement or Breakthrough? The Link between Goal Orientation, Employee Learning, Creativity and Job Performance.

Christensen, E. W. and Gordon, G. G. (1999). An Exploration of Industry, Culture and Revenue Growth. Organization studies 20(3): 397. 
Chughtai, A. A. and Buckley, F. (2011). Work Engagement: Antecedents, the Mediating Role of Learning Goal Orientation and Job Performance. Career Development International 16(7): 684-705.

Clarke, N. (2005). Workplace Learning Environment and Its Relationship with Learning Outcomes in Healthcare Organizations. Human Resource Development International 8(2): 185-205.

Cromwell, S. E. and Kolb, J. A. (2004). An Examination of Workplace Environment Support Factors Affecting Transfer of Supervisory Skills Training to the Workplace. Human Resource Development Quarterly 15(4): 449-471.

Dawis, R. V. and Lofquist, L. H. (1984). A Psychological Theory of Work Adjustment: An Individual-Differences Model and Its Applications, University of Minnesota Press Minneapolis, MN.

Denison, D. R. (1996). What Is the Difference between Organizational Culture and Organizational Climate? A Native's Point of View on a Decade of Paradigm Wars. Academy of Management review: 619-654.

Detert, J. R., Schroeder, R. G. and Mauriel, J. J. (2000). A Framework for Linking Culture and Improvement Initiatives in Organizations. Academy of management review: 850-863.

Dysvik, A. and Kuvaas, B. (2008). The Relationship between Perceived Training Opportunities, Work Motivation and Employee Outcomes. International Journal of Training and Development 12(3): 138-157.

Elfenbein, H. A. and O'Reilly, C. A. (2007). Fitting In: The Effects of Relational Demography and Person-Culture Fit on Group Process and Performance. Group \& Organization Management 32(1): 109-142.

Enos, M. D., Kehrhahn, M. T. and Bell, A. (2003). Informal Learning and the Transfer of Learning: How Managers Develop Proficiency. Human Resource Development Quarterly 14(4): 369-387.

Eraut, M. (2002). The Interaction between Qualifications and Work-Based Learning. Working to learn, transforming learning in the workplace: 63-78.

Garavan, T. N., McGuire, D. and O’Donnell, D. (2004). Exploring Human Resource Development: A Levels of Analysis Approach. Human Resource Development Review 3(4): 417.

Heilmann, P. (2007). High Level Competence: A Tool for Coping with Organizational 
Change. Journal of European Industrial Training 31(9): 727-741.

Hochwarter, W. A., Witt, L., Treadway, D. C. and Ferris, G. R. (2006). The Interaction of Social Skill and Organizational Support on Job Performance. Journal of Applied Psychology 91(2): 482.

Hofstede, G. (1993). Cultural Constraints in Management Theories. The Executive: 81-94.

Hofstede, G., Neuijen, B., Ohayv, D. D. and Sanders, G. (1990). Measuring Organizational Cultures: A Qualitative and Quantitative Study across Twenty Cases. Administrative Science Quarterly: 286-316.

Holton III, E. F., Bates, R. A., Bookter, A. I. and Yamkovenko, V. B. (2007). Convergent and Divergent Validity of the Learning Transfer System Inventory. Human Resource Development Quarterly 18(3): 385-419.

Jacobs, R. L. and Park, Y. (2009). A Proposed Conceptual Framework of Workplace Learning: Implications for Theory Development and Research in Human Resource Development. Human Resource Development Review 8(2): 133.

Janssen, O. and Van Yperen, N. W. (2004). Employees' Goal Orientations, the Quality of Leader-Member Exchange, and the Outcomes of Job Performance and Job Satisfaction. Academy of Management journal 47(3): 368-384.

Jo, S. J. and Joo, B.-K. (2011). Knowledge Sharing: The Influences of Learning Organization Culture, Organizational Commitment, and Organizational Citizenship Behaviors. Journal of Leadership \& Organizational Studies 18(3): 353-364.

Joo, B.-K. B. (2012). Leader Member Exchange Quality and in-Role Job Performance the Moderating Role of Learning Organization Culture. Journal of Leadership \& Organizational Studies 19(1): 25-34.

Keith, N. and Frese, M. (2011). Enhancing Firm Performance and Innovativeness through Error Management Culture. Handbook of organizational culture and climate: 137-157.

Klein, K. I., Tosi, H. and Cannella, A. A. (1999). Multilevel Theory Building: Benefits, Barriers, and New Developments. Academy of management review 24: 243-248.

Kramer, H. (2007). Measuring the Effect of E-Learning on Job Performance, ProQuest.

Kristof-Brown, A. L. and Stevens, C. K. (2001). Goal Congruence in Project Teams: Does the Fit between Members' Personal Mastery and Performance Goals Matter? Journal of Applied Psychology 86(6): 1083. 
Lankau, M. J. and Scandura, T. A. (2002). An Investigation of Personal Learning in Mentoring Relationships: Content, Antecedents, and Consequences. Academy of management Journal: 779-790.

Lin, T. Y. (2008). Organizational Culture, Knowledge Circulation Processes, and Job Performance.

Lynch, R., Leo, S. and Downing, K. (2006). Context Dependent Learning: Its Value and Impact for Workplace Education. Education+ Training 48(1): 15-24.

MacIntosh, E. W. and Doherty, A. (2010). The Influence of Organizational Culture on Job Satisfaction and Intention to Leave. Sport Management Review 13(2): 106-117.

Magee, K. C. (2002). The Impact of Organizational Culture on the Implementation of Performance Management. Georgia State University.

Marsick, V. J. and Watkins, K. E. (2003). Demonstrating the Value of an Organization's Learning Culture: The Dimensions of the Learning Organization Questionnaire. Advances in Developing Human Resources 5(2): 132.

Mathieu, J. E. and Farr, J. L. (1991). Further Evidence for the Discriminant Validity of Measures of Organizational Commitment, Job Involvement, and Job Satisfaction. Journal of Applied Psychology 76(1): 127.

Mathieu, J. E., Hofmann, D. A. and Farr, J. L. (1993). Job Perception-Job Satisfaction Relations: An Empirical Comparison of Three Competing Theories. Organizational Behavior and Human Decision Processes 56(3): 370-387.

Maurer, T. J., Lippstreu, M. and Judge, T. A. (2008). Structural Model of Employee Involvement in Skill Development Activity: The Role of Individual Differences. Journal of Vocational Behavior 72(3): 336-350.

Meador, D. P. (2008). Modeling Training Effects on Task Performance Using a Human Performance Taxonomy. Wright State University. Fairborn, Ohio

Mintu-Wimsatt, A. (2002). Personality and Negotiation Style: The Moderating Effects of Cultural Context. Thunderbird International Business Review 44(6): 729-748.

Miron, E., Erez, M. and Naveh, E. (2004). Do Personal Characteristics and Cultural Values That Promote Innovation, Quality, and Efficiency Compete or Complement Each Other? Journal of Organizational Behavior 25(2): 175-199. 
Moon, S.-Y. and Na, S.-I. (2009a). Psychological and Organizational Variables Associated with Workplace Learning in Small and Medium Manufacturing Businesses in Korea. Asia Pacific Education Review 10(3): 327-336.

Moon, S. Y. and Na, S. I. (2009b). Psychological and Organizational Variables Associated with Workplace Learning in Small and Medium Manufacturing Businesses in Korea. Asia Pacific Education Review 10(3): 327-336.

Motowidlo, S. J. and Van Scotter, J. R. (1994). Evidence That Task Performance Should Be Distinguished from Contextual Performance. Journal of Applied Psychology 79(4): 475.

O'Reilly III, C. A., Caldwell, D. F. and Barnett, W. P. (1989). Work Group Demography, Social Integration, and Turnover. Administrative science quarterly: 21-37.

O'Reilly III, C. A., Chatman, J. and Caldwell, D. F. (1991). People and Organizational Culture: A Profile Comparison Approach to Assessing Person-Organization Fit. Academy of management Journal: 487-516.

Park, Y. (2009). The Relationships among Investment in Workplace Learning, Organizational Perspective on Human Resource Development, Organizational Outcomes of Workplace Learning, and Organizational Performance Using the Korea 2005 and 2007 Human Capital Corporate Panel Surveys. The Ohio State University.

Podsakoff, P. M., MacKenzie, S. B., Lee, J.-Y. and Podsakoff, N. P. (2003). Common Method Biases in Behavioral Research: A Critical Review of the Literature and Recommended Remedies. Journal of Applied Psychology 88(5): 879.

Poell, R. F. and Woerkom, M. (2011). Introduction: Supporting Workplace Learning. Supporting Workplace Learning: 1-7.

Reio, T. G. and Callahan, J. L. (2004). Affect, Curiosity, and Socialization-Related Learning: A Path Analysis of Antecedents to Job Performance. Journal of Business and Psychology 19(1): 3-22.

Reio, T. G. and Wiswell, A. (2000). Field Investigation of the Relationship among Adult Curiosity, Workplace Learning, and Job Performance. Human Resource Development Quarterly 11(1): 5-30.

Rothwell, W. J. (2002). The Workplace Learner: How to Align Training Initiatives with Individual Learning Competencies, AMACOM/American Management Association.

Rowden, R. W. (2002). The Relationship between Workplace Learning and Job Satisfaction in Us Small to Midsize Businesses. Human Resource Development Quarterly 13(4): 407-425. 
Sarris, A. and Kirby, N. (2005). Antarctica: A Study of Person-Culture Fit. Australian journal of psychology 57(3): 161-169.

Schein, E. H. (1990). Organizational Culture. American psychologist 45(2): 109.

Schein, E. H. (1996). Culture: The Missing Concept in Organization Studies. Administrative Science Quarterly: 229-240.

Scott, S. G. and Bruce, R. A. (1994). Determinants of Innovative Behavior: A Path Model of Individual Innovation in the Workplace. Academy of Management journal 37(3): 580-607.

Shader, K. K. (1990). An Investigation of the Possible Impact of Training and Organizational Culture on Technical Employee Job Performance. Florida State University.

Somech, A. and Drachâ€• Zahavy, A. (2004). Exploring Organizational Citizenship Behaviour from an Organizational Perspective: The Relationship between Organizational Learning and Organizational Citizenship Behaviour. Journal of Occupational and Organizational Psychology 77(3): 281-298.

Swanson, R. A. and Holton, E. F. (1999). Results: How to Assess Performance, Learning, \& Perceptions in Organizations, Berrett-Koehler Publishers.

Tracey, J. B., Tannenbaum, S. I. and Kavanagh, M. J. (1995). Applying Trained Skills on the Job: The Importance of the Work Environment. Journal of Applied Psychology 80(2): 239.

Tsai, W. C. and Tai, W. T. (2003). Perceived Importance as a Mediator of the Relationship between Training Assignment and Training Motivation. Personnel Review 32(2): 151-163.

Velada, R., Caetano, A., Michel, J. W., Lyons, B. D. and Kavanagh, M. J. (2007). The Effects of Training Design, Individual Characteristics and Work Environment on Transfer of Training. International Journal of Training and Development 11(4): 282-294.

Verbeke, W. (2001). The Emerging Role of Traceability and Information in Demand-Oriented Livestock Production. Outlook on agriculture 30(4): 249-255.

Wang, H., Begley, T., Hui, C. and Lee, C. (2012). Are the Effects of Conscientiousness on Contextual and Innovative Performance Context Specific? Organizational Culture as a Moderator. The International Journal of Human Resource Management 23(1): 174-189.

Watkins, K. E. and Marsick, V. J. (1997). Dimensions of the Learning Organization Questionnaire. Warwick, RI: Partners for the Learning Organization. 


\section{Macrothink

Yiing, L. H. and Ahmad, K. Z. B. (2009). The Moderating Effects of Organizational Culture on the Relationships between Leadership Behaviour and Organizational Commitment and between Organizational Commitment and Job Satisfaction and Performance. Leadership \& Organization Development Journal 30(1): 53-86. 